\title{
Upregulation of Fas-signalling molecules in lung epithelial cells from patients with idiopathic pulmonary fibrosis
}

\author{
T. Maeyama, K. Kuwano, M. Kawasaki, R. Kunitake, N. Hagimoto, T. Matsuba, M. Yoshimi, \\ I. Inoshima, K. Yoshida, N. Hara
}

Upregulation of Fas-signalling molecules in lung epithelial cells from patients with idiopathic pulmonary fibrosis. T. Maeyama, K. Kuwano, M. Kawasaki, R. Kunitake, N. Hagimoto, T. Matsuba, M. Yoshimi, I. Inoshima, K. Yoshida, N. Hara. (C)ERS Journals Ltd 2001.

ABSTRACT: The caspase cascade is an executioner of apoptosis, mediated by Fas. Fas-associating protein with death domain (FADD) interacts with Fas and initiates apoptosis through activating caspase-8. It has previously been demonstrated that the Fas-Fas ligand pathway may be involved in the pathophysiology of idiopathic pulmonary fibrosis (IPF). The aim of this study was to investigate Fas-signalling molecules in epithelial cells in IPF.

The immunohistochemistry for FADD and caspase-1 and -3 and terminal deoxynucleotidyl transferase-mediated deoxyuridinetriphosphate nick endlabelling (TUNEL) methods were performed in lung tissues from 10 patients with IPF obtained by thoracoscopic biopsy and in seven normal lung parenchyma specimens. The induction of caspases expression and activation by Fas-ligation on lung epithelial cell line A549 was also investigated.

The immunoreactivity grade for FADD and caspase-1 and $\mathbf{- 3}$, and positive signals for TUNEL were significantly increased in epithelial cells of IPF compared with controls. Fas-ligation induced upregulation of caspase-1 and -3 expression in the nucleus and cytoplasm in A549 cells. Procaspase-1, -3, and -8 were activated in apoptotic cells, but not in viable cells.

Although direct measurement of the caspase activity in lung epithelial cells of idiopathic pulmonary fibrosis could not be made, these results suggest that the Fassignalling pathway is upregulated in lung epithelial cells of idiopathic pulmonary fibrosis.

Eur Respir J 2001; 17: 180-189.
Research Institute for Diseases of the Chest, Graduate School of Medical Sciences, Kyushu University, Fukuoka, Japan.

Correspondence: K. Kuwano,

Research Institute for Diseases of the Chest, Faculty of Medicine Kyushu University, 3-1-1, Maidashi, Higashiku Fukuoka, 812-8582, Japan

Fax: 81-926425389

Keywords: Apoptosis

caspase

pulmonary fibrosis

Received: September 101999

Accepted after revision September 15 2000

This work was supported by a Grantin-Aid for Scientific Research (09670620) from the Ministry of Education, Science and Culture of Japan.
Apoptosis is regulated cell death observed under a variety of physiological and pathological conditions. Inappropriate apoptosis leads to a variety of diseases such as the immunodeficiency and autoimmune disorders, and malignancies [1 - 3]. Idiopathic pulmonary fibrosis (IPF) is a chronic and often fatal pulmonary disease. Although the aetiology of IPF is still unknown, the disease is characterized by interstitial fibrosis following chronic alveolitis. It has previously been demonstrated that deoxyribonucleic acid (DNA) damage and apoptosis were present in bronchiolar and alveolar epithelial cells in IPF [4], and it was suggested that epithelial cell death might lead to replacement by fibroblasts. It has also been reported that Fas was upregulated in lung epithelial cells, whereas the Fas-ligand (FasL) was expressed in infiltrating inflammatory cells in IPF [5]. Therefore, Fas-mediated apoptosis may be involved in the pathogenesis of IPF.

The interleukin-1 $\beta$ converting enzyme (ICE) family has recently been identified to play an essential role in the process of apoptosis in several systems, including Fas-mediated apoptosis [6-9]. Fourteen members of the ICE/cell death abnormal-3 (CED-3) cysteine protease family have been identified [10-13], and named caspases [14]. During apoptosis, inactive caspases are cleaved at Asp-X sites, generating a large and small subunit, which together constitute the active caspase. A cascade of proteolysis beginning with the activation of "initiator" caspases, for example caspase-8, leads to the activation of "effector" caspases, such as caspase-3, which subsequently cleave substrates including polyadenosine diphosphate ((ADP)-ribose) polymerase, lamins and DNA-dependent protein kinase, resulting in the morphological features of apoptosis $[11,15]$. Fas-associating protein with death domain (FADD) is a signal transducer downstream of Fas [16]. Following FasL ligation to Fas, Fas binds to FADD through its intracellular death domain. FADD binds to caspase- 8 through its death effector domain and makes a form of death-inducing signalling complex, leading to the activation of caspase- 8 .

To assess whether FADD and caspases may associate with DNA damage and apoptosis of lung epithelial cells in IPF, this study investigated the expression of FADD, caspase-1 and caspase-3, in lung tissues from patients with IPF, and compared the results of immunohistochemistry with the number of 


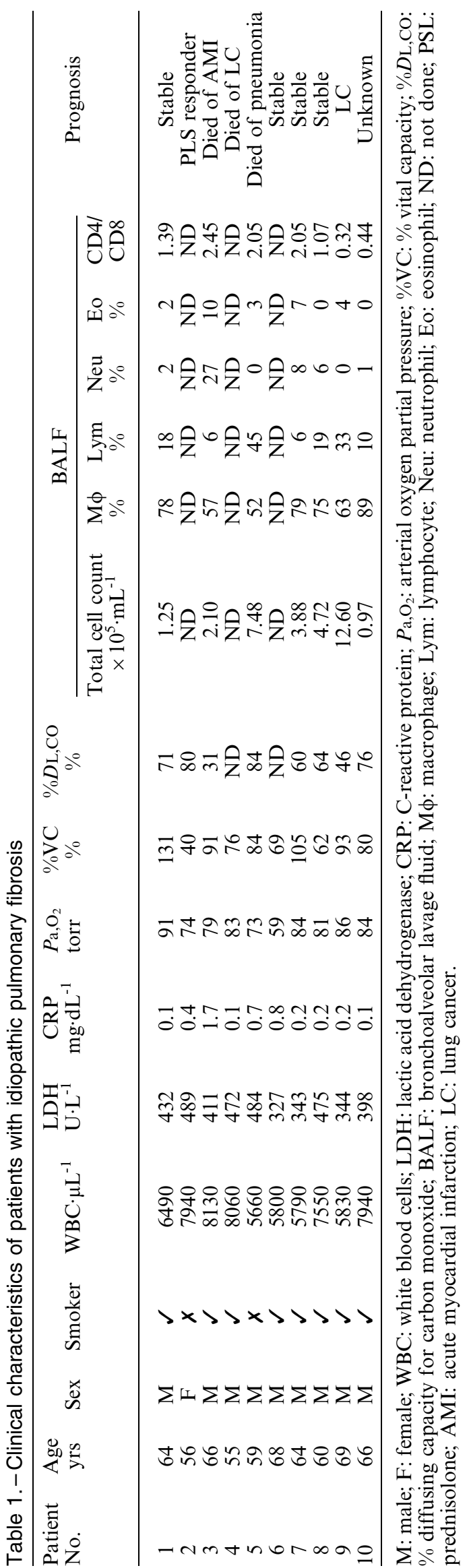

apoptotic cells assessed by terminal deoxynucleotidyl transferase-mediated deoxyuridine triphosphate (dUTP) nick endlabelling (TUNEL) methods. Since it was found that the immunoreactivity for caspases was detected in the nucleus as well as the cytoplasm of lung epithelial cells of IPF by the immunohistochemistry, it was examined whether caspases translocate from the cytoplasm to the nucleus when activated by the Fasligation using a human lung epithelial cell line (A459). It was also examined whether the cells in which caspases are upregulated and activated by Fas-ligation, are actually undergoing apoptosis.

\section{Materials and methods}

\section{Case material}

This study of IPF was performed on lung samples obtained by thoracoscopic lung biopsy. The clinical data of 10 patients with IPF are presented in table 1 . There were nine males and one female, whose ages ranged from 55-69 yrs (mean 63 yrs). Eight were smokers and two were nonsmokers. The diagnosis of IPF was established by a combination of medical history, physical examination, laboratory tests, chest radiographs, pulmonary function tests, and the results of histological findings, according to previously described criteria [17]. The histological findings in lung biopsy specimens from all patients with IPF were compatible with those of UIP. The results in IPF were compared with those in seven normal lung parenchyma specimens obtained by lobectomy for lung cancer of the solitary pulmonary nodule. These were four males and three females, whose ages ranged from 56-78 yrs (mean $67 \mathrm{yrs}$ ), and all were smokers.

\section{Tissue preparation}

Tissue samples were fixed in 10\% formalin overnight, and embedded in paraffin. A 5- $\mu$ m paraffin section was adhered to slides pretreated with poly-L-lysine. These sections were dewaxed by washing three times for $5 \mathrm{~min}$ each in xylene, then dehydrated in $100 \%, 95 \%$, and $80 \%$ ethanol for $5 \mathrm{~min}$ each, and finally rinsed with distilled water.

Immunohistochemistry for fas-associating protein with death domain and caspases in lung tissues

Hydrated autoclaving was used as a pretreatment to immunostaining for caspase-1 and FADD, as previously described by SHIN et al. [18]. Following deparaffinization in xylene and rehydration in ethanol, the tissue sections were autoclaved at $121^{\circ} \mathrm{C}$ for $20 \mathrm{~min}$ in a glass pot filled with distilled water to completely immerse the sections and washed three times in $0.1 \mathrm{M}$ phosphate buffered saline (PBS). Immunohistochemistry was performed using a modified streptavidin-biotinylated peroxidase technique using a Histofine SAB-PO kit (Nichirei Corporation, Tokyo, Japan). Nonspecific protein staining was blocked by rabbit 

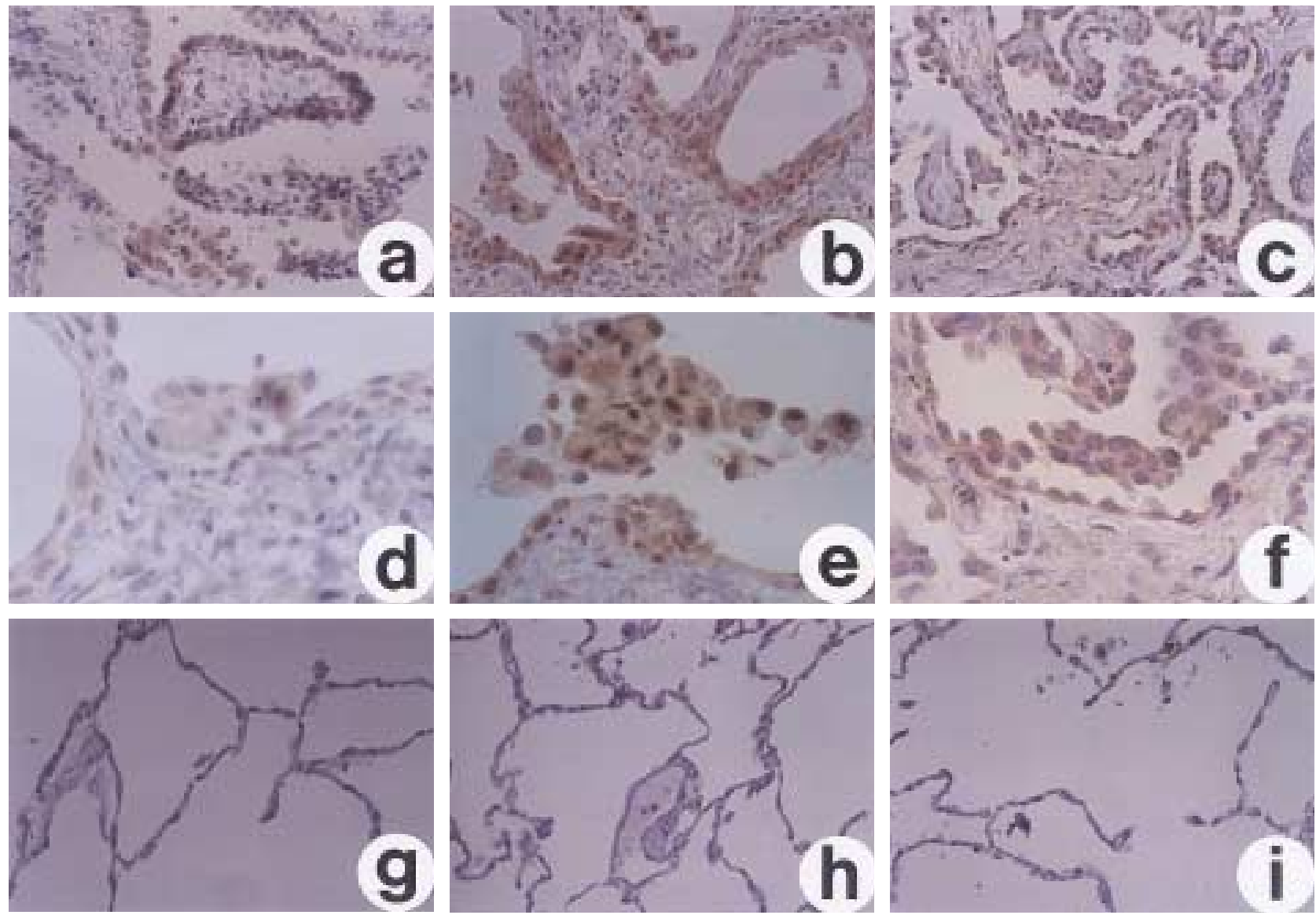

Fig. 1. - Immunohistochemical analysis of Fas-associating protein with death domain (FADD), caspase-1 and caspase-3. FADD (a, d) was detected in the cytoplasm, and caspase-1 (b, e), and caspase-3 (c, f) were detected in both cytoplasm and nucleus of bronchiolar and alveolar epithelial cells in lung tissues of IPF. Positive signals for FADD and caspases were also found in macrophages. The intensity of these signals was not detected in normal lung parenchyma ( $\mathrm{g}, \mathrm{h}$ and $\mathrm{i}$, respectively) (original magnification, a, b, c, g, h, i; $\times 62.5, \mathrm{~d}, \mathrm{e}, \mathrm{f} ; \times 125)$.

serum for $30 \mathrm{~min}$ at room temperature. The sections were incubated with goat anti-FADD polyclonal antibody (Santa Cruz Biotechnology, Santa Cruz, CA, USA), goat anti-caspase-1 polyclonal antibody (Santa Cruz Biotechnology), and goat anti-caspase-3 polyclonal antibody (Santa Cruz Biotechnology) at $4^{\circ} \mathrm{C}$ overnight. The sections were rinsed with PBS and incubated with biotinylated anti-goat immunoglobulin $\mathrm{G}(\mathrm{IgG})$ for $30 \mathrm{~min}$, washed, and treated with $0.3 \%$ hydrogen peroxide in methanol for $30 \mathrm{~min}$ to inhibit the activity of any endogenous peroxide. The slides were washed, incubated with a streptavidin-biotinperoxidase complex for $30 \mathrm{~min}$, and developed according to the manufacturer's directions. The sections were subsequently counterstained with haematoxylin and mounted. The degree of staining was graded from $0-3$ according to the percentage of immunoreactive cells: 0 , $0 \% ; 1,<10 \% ; 2,10-50 \% ; 3,>50 \%$.

\section{Apoptosis analysis in lung tissues}

Apoptosis was detected by the TUNEL method using a commercially available kit (Takara Biomedi- cals, Kusatsu, Japan). After proteinase digestion and removal of endogenous peroxidase, the sections were incubated in a mixture containing terminal deoxynucleotidyl transferase (TdT) and fluorescein isothiocyanate-labelled dUTP. The sections were then treated with the peroxidase labelled with antifluorescein isothiocyanate antibody. The reaction products were developed with 3,3'-diaminobenzidine tetrahydrochloride and counterstained with methyl green. The number of positive cells for TUNEL in the whole area of the section was counted under the microscope with $\times 250$ magnification.

The treatment of lung epithelial cell line (A549 cells) with anti-Fas antibody

The human lung epithelial cell line, A549, was cultured in Roswell Park Memorial Institute (RPMI) 1640 medium (Sigma Chemical Co, St Louis, MO, USA) with $10 \%$ foetal bovine serum (FBS, GIBCOBRL, Grand Island, NY, USA), penicillin and streptomycin in an incubator with $5 \% \mathrm{CO}_{2}$ at $37^{\circ} \mathrm{C}$. For induction of apoptosis, interferon-gamma (IFN- $\gamma$ ) 


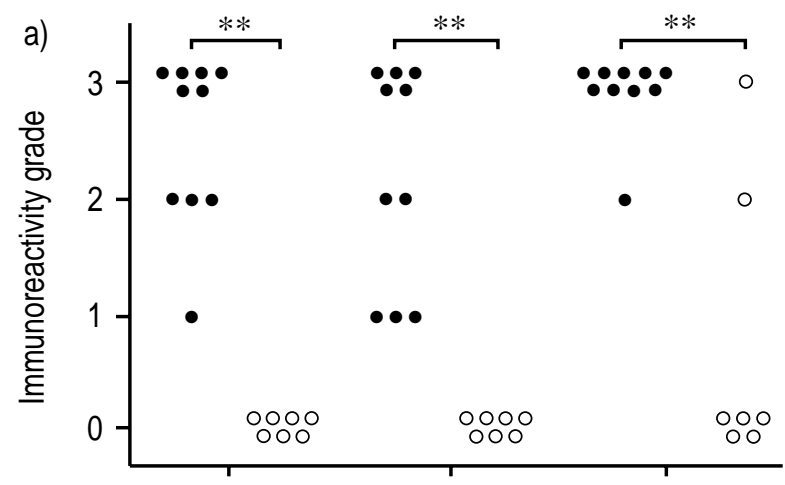

b)
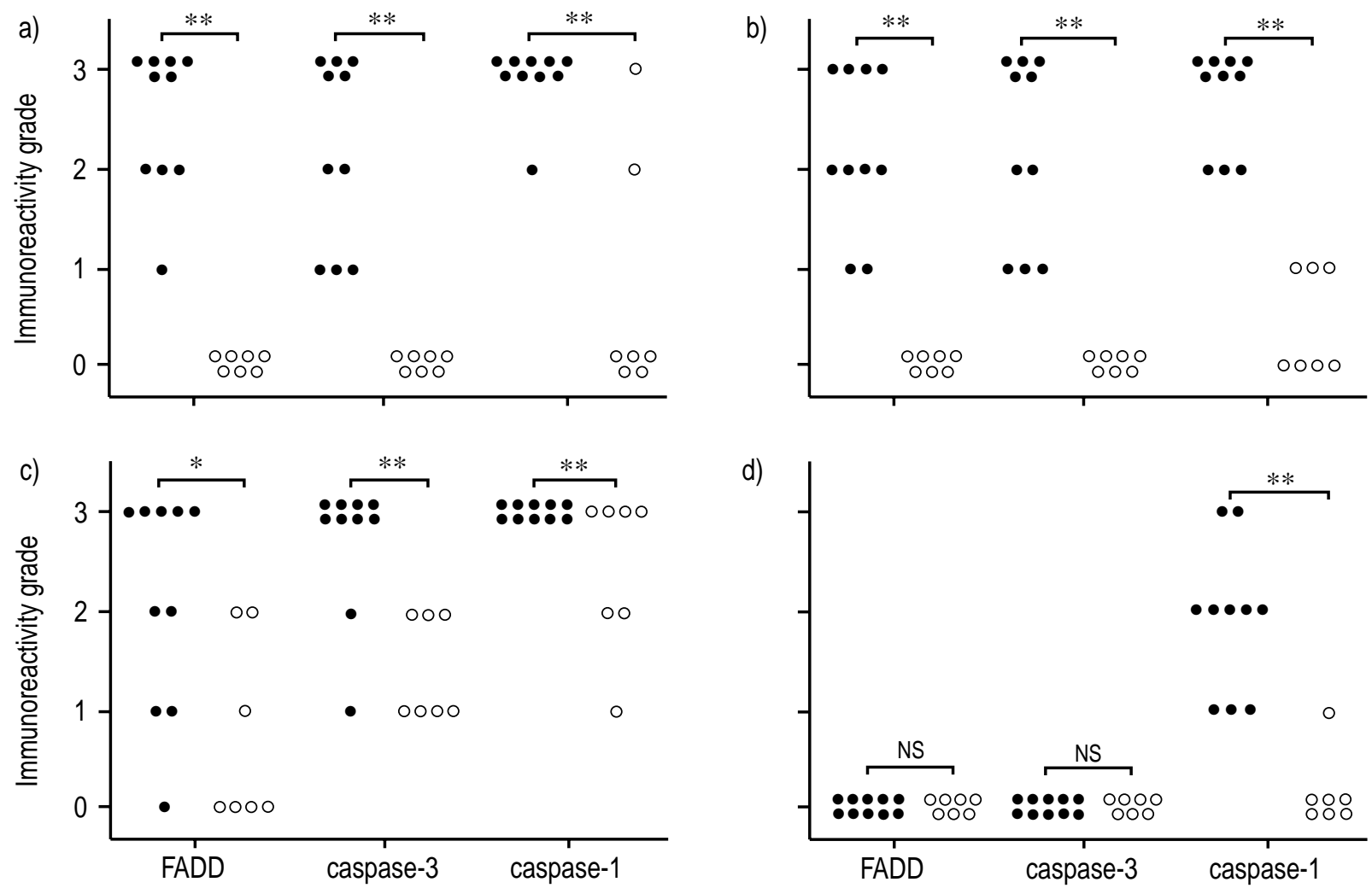

Fig. 2. - Summary of immunostaining grade for Fas-associating protein with death domain (FADD), caspase-1, and caspase-3 in a) bronchiolar and b) alveolar epithelial cells, c) alveolar macrophages, and d) lymphocytes. Each circle represents one individual. Closed circles are patients with idiopathic pulmonary fibrosis and open circles are control patients. * ${ }^{*}<0.05$; ${ }^{* *}$ : $p<0.01$; NS: nonsignificant.

and agonistic anti-Fas monoclonal antibody treatment was used, as described previously [19]. In brief, cells were treated with $100 \mathrm{ng} \cdot \mathrm{mL}^{-1}$ agonistic anti-Fas monoclonal antibody (CH-11; MBL, Nagoya, Japan) or isotype-matched mouse immunoglobulin-M (IgM) (MBL, Nagoya, Japan) as a control of $\mathrm{CH}-11$ in culture medium after pretreatment with $40 \mathrm{ng} \cdot \mathrm{mL}^{-1}$ IFN- $\gamma$ (Shionogi, Osaka, Japan) for $6 \mathrm{~h}$. The cells were harvested $24 \mathrm{~h}$ after the addition of $\mathrm{CH}-11$, and prepared for flow cytometry, caspase activity assay, western blot, and immunocytochemistry.

\section{Apoptosis analysis of A549 cells}

Apoptosis of A549 cells were monitored for DNA fragmentation with propidium iodide (PI). After being washed with PBS, cells were fixed with $70 \%$ ethanol for $1 \mathrm{~h}$ at $4^{\circ} \mathrm{C}$. Cells were resuspended and incubated in PBS with $0.5 \mathrm{mg}$ of ribonuclease A and $100 \mu \mathrm{g}$ of PI for $15 \mathrm{~min}$ at room temperature in the dark. Cells were washed and resuspended with $1.0 \mathrm{~mL}$ of PBS and analysed on a Coulter EPICSXL flow cytometer (Coulter, Luton, United Kingdom).

\section{Activity of caspases on A549 cells}

Activity of caspase-1 and caspase-3 was determined using fluorometric CaspACE ${ }^{\mathrm{TM}}$ Assay System (Pro- mega, Madison, WI, USA). In brief, cell protein extracts were prepared by homogenization of $1 \times 10^{6}$ cells in a hypotonic buffer $(25 \mathrm{mM}$ Hepes, $\mathrm{pH} 7.5,5 \mathrm{mM} \mathrm{MgCl}_{2}, 1 \mathrm{mM}$ ethyleneglycol-bis-( $\beta$ aminoethylether)-N,N, $\mathrm{N}^{\prime}, \mathrm{N}^{\prime}$-tetraacetic acid (EGTA), $1 \mathrm{mM}$ phenylmethylsulphonyl fluoride (PMSF), $1 \mu \mathrm{g} \cdot \mathrm{mL}^{-1}$ leupeptin and aprotinin). Homogenates were centrifuged at $12,000 \times g$ for $10 \mathrm{~min}$ and supernatants were collected. Twenty $\mu \mathrm{g}$ of the extracted proteins were incubated with the fluorescent tetrapeptide substrates Ac-YVAD-AMC for caspase-1 or AcDEVD-AMC for caspase-3. The fluorescence of cleaved substrates was determined using a spectrofluorometer set at an excitation wavelength of $360 \mathrm{~nm}$ and an emission wavelength of $460 \mathrm{~nm}$.

\section{Immunocytochemistry for caspases on A549 cells}

After removing the culture medium and rinsing with PBS, cells were fixed with $10 \%$ formalin for $5 \mathrm{~min}$. Cells were resuspended in $500 \mu \mathrm{L}$ of $10 \%$ formalin, and three drops of the suspension were placed into the mould with same amount of molten, low-melting point $2 \%$ agarose. The agarose blocks were embedded in paraffin. A $5-\mu \mathrm{m}$ paraffin section on the slide was dewaxed by washing in xylene, then dehydrated. Immunocytochemistry for caspase-1 and caspase-3 

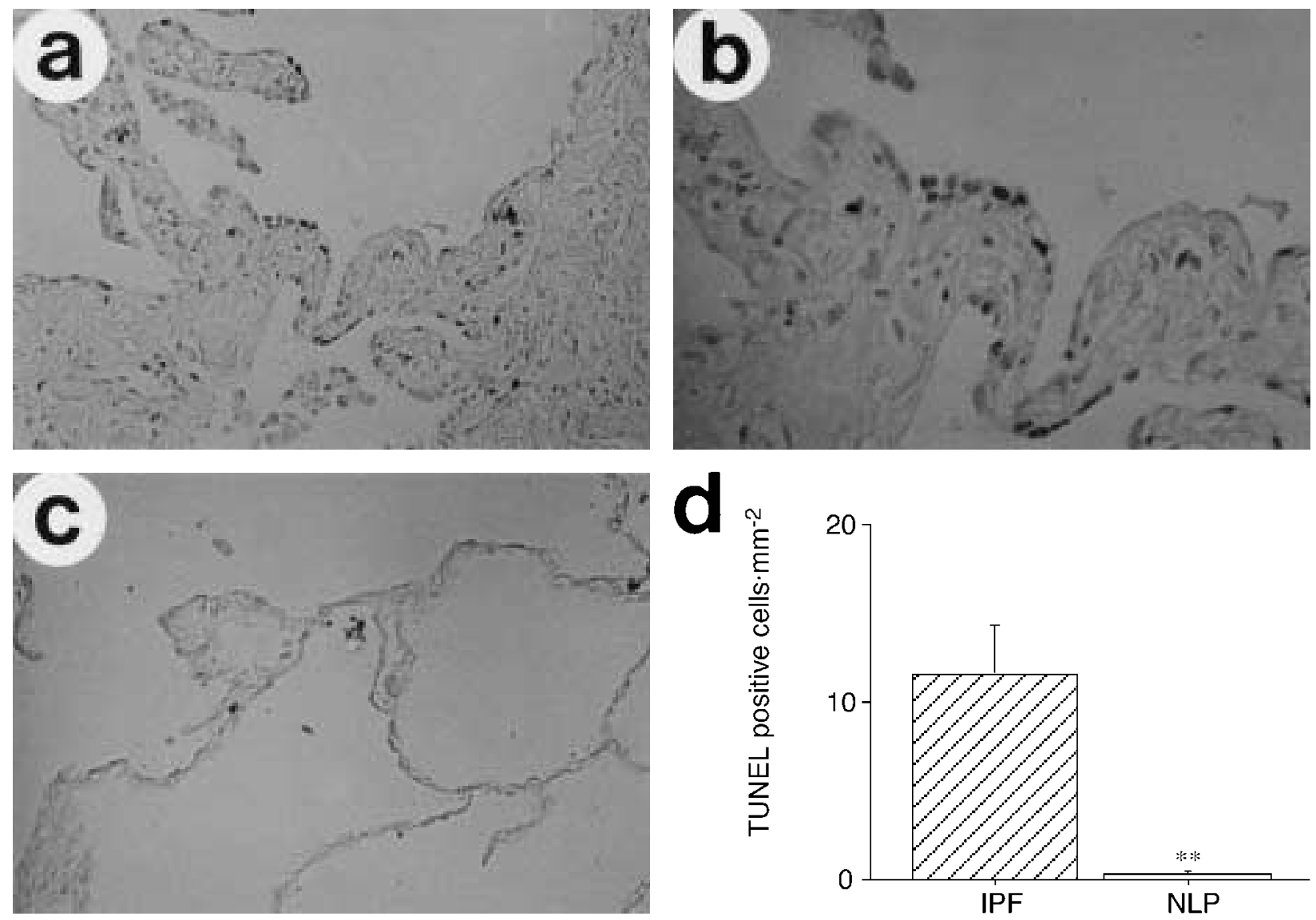

Fig. 3. - Representative results of terminal deoxynucleotidyl transferase-mediated deoxyuridinetriphosphate nick endlabelling (TUNEL) staining. The positive signals for TUNEL staining were predominantly detected in a) bronchiolar and b) alveolar epithelial cells. There were few positive signals in c) normal lung parenchyma; d) the number of TUNEL positive cells in lung tissues was significantly increased $(\mathrm{p}<0.01)$ in idiopathic pulmonary fibrosis (IPF) compared with the normal lung parenchyma (NLP) (original magnification, $\mathrm{a}, \mathrm{c} ; \times 62.5, \mathrm{~b} ; \times 125)$.

was performed as described in Immunohistochemistry for fas-associating protein with death domain and caspases in lung tissues as that in lung tissues without hydrated autoclaving.

\section{Western blot analysis for caspases on A549 cells}

After administration of $\mathrm{CH}-11$ with IFN- $\gamma$ pretreatment, detached cells and attached cells were collected separately. Cell protein extracts were prepared by homogenization of $1 \times 10^{6}$ cells in a sample buffer (500 mM tris-(hydroxymethyl)-aminomethane (Tris)$\mathrm{HCl} \mathrm{pH} 6.8,2 \%$ sodium dodecyl sulphate (SDS), 10\% glycerol, $0.6 \%$ mercaptoethanol) and were boiled for 2 min. Proteins were separated by SDS-polyacrylamide gel electrophoresis (SDS-PAGE). After SDS-PAGE, the proteins were transferred to polyvinylidene fluoride hydrophobic membrane (Millipore, Bedford, MA, USA). Membranes were blocked by $5 \%$ nonfat drymilk in Tris buffer saline containing $0.05 \%$ Tween-20 (TBST) at $4{ }^{\circ} \mathrm{C}$ overnight. The membranes were rinsed with TBST and incubated with primary antibody in blocking buffer at $4{ }^{\circ} \mathrm{C}$ overnight. After a rinse, the membranes were incubated with biotinylated anti-goat $\mathrm{IgG}$ for
$30 \mathrm{~min}$ at room temperature. The blots were developed with enhanced chemiluminesence method (Amersham, Piscataway, NJ, USA).

\section{Statistics}

The difference in the number of TUNEL positive cells and the difference in caspase activity were analysed by unpaired t-tests. The difference in the immunoreactivity grade was analysed by Mann-Whitney's Utest. The correlation between the immunoreactivity grade and the number of TUNEL positive cells was assessed by Spearman's rank correlation coefficient. A p-value of $<0.05$ was considered statistically significant.

\section{Results}

Immunohistochemistry in lung tissues

Alveolar and bronchiolar epithelium. The expression of FADD, caspase-1, and caspase-3 were detected in alveolar and bronchiolar epithelial cells in lung tissues 
a)

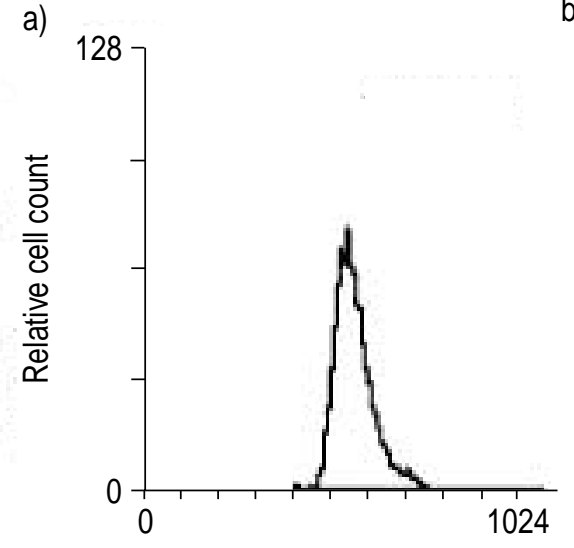

b)

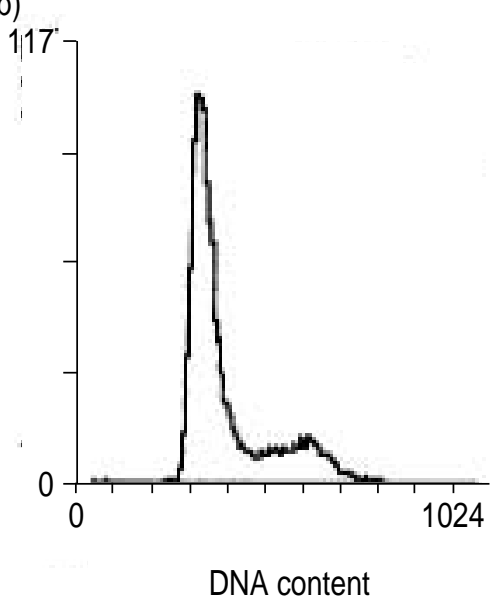

c)

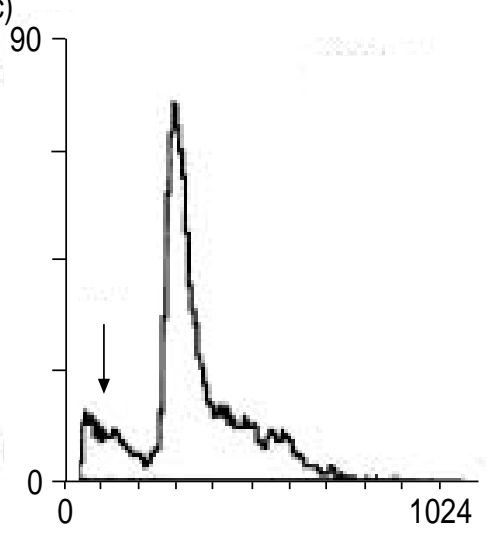

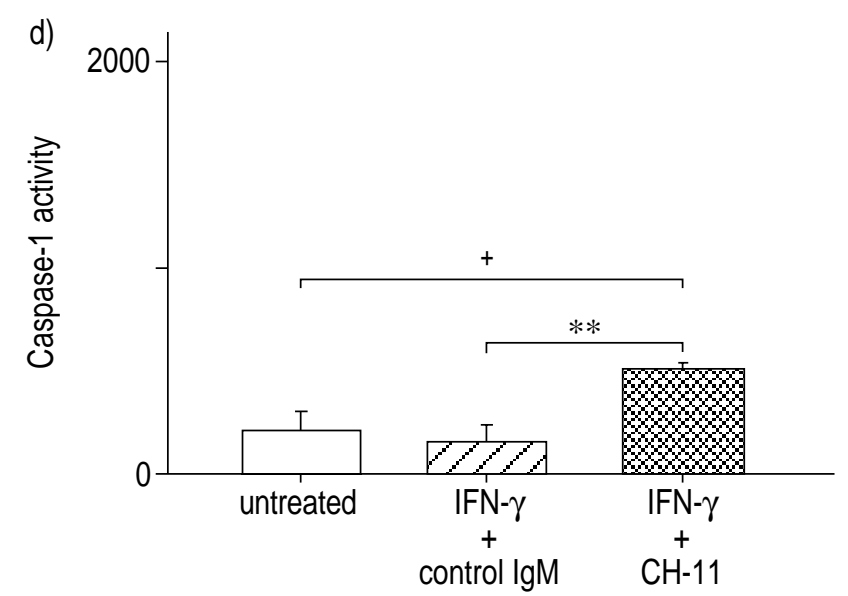

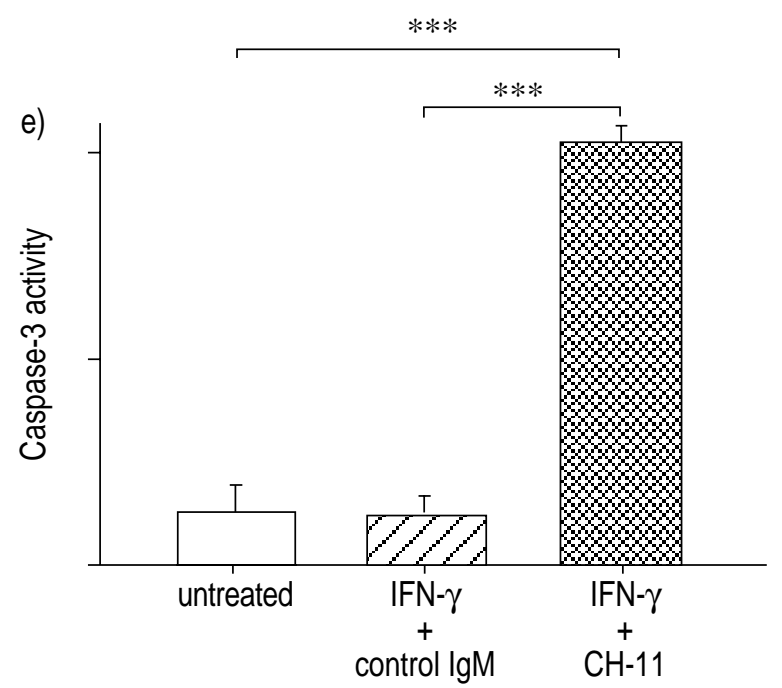

Fig. 4. - Flow cytometric analysis of CH-11-induced apoptosis on A549 cells by propidium iodide (PI) staining in a) untreated cells, b) cells with control immunoglobulin $\mathrm{M}$ (IgM) and interferon- $\gamma$ (IFN- $\gamma$ ) and c) cells treated with IFN- $\gamma$ and CH-11. Compared with untreated cells or cells with control IgM and IFN- $\gamma$ pretreatment alone, apoptotic cells are evident as indicated by the arrow. d) Caspase- 1 and e) caspase-3 activity in A549 cells. Caspase-1 and caspase-3 activity in A549 cells were significantly increased after the administration of $\mathrm{CH}-11$ with IFN- $\gamma$ pretreatment compared with those in untreated cells or cells administered control IgM with IFN$\gamma$ pretreatment. ${ }^{+}: \mathrm{p}<0.005 ; * *: \mathrm{p}<0.01 ; * * *: \mathrm{p}<0.001$.

from patients with IPF, whereas the positive signals for these proteins were negative or weak in normal lung parenchyma. Positive signals for FADD were found in the cytoplasm. Positive signals for caspase-1 and caspase-3 were found not only in the cytoplasm but also in the nucleus of the cells (fig. 1). The immunoreactivity grade for FADD, caspase-1, and caspase-3 were significantly upregulated in alveolar and bronchiolar epithelial cells in IPF, compared with normal lung parenchyma (fig. 2).

Alveolar macrophage. Positive signals for FADD were found in the cytoplasm, and those for caspase-1 and caspase- 3 were detected in the nucleus, as well as in the cytoplasm, of alveolar macrophages in IPF and normal lung parenchyma (fig. 1). The immunoreactivity grades for these proteins were significantly higher in lung tissues of IPF than those in normal lung parenchyma (fig. 2).

Lymphocyte. The immunoreactivity for FADD or caspase-3 was not detected in lymphocytes in either IPF or normal lung parenchyma, whereas that for caspase-1 was detected in the cytoplasm and nucleus of lymphocytes in IPF, but not in normal lung parenchyma (fig. 1). The immunoreactivity grade for these proteins was higher in IPF compared with normal lung parenchyma (fig. 2).

\section{TUNEL assay in lung tissues}

TUNEL demonstrated positive signals predominantly in bronchiolar and alveolar epithelial cells in IPF (fig. 3), whereas there were few positive signals in 

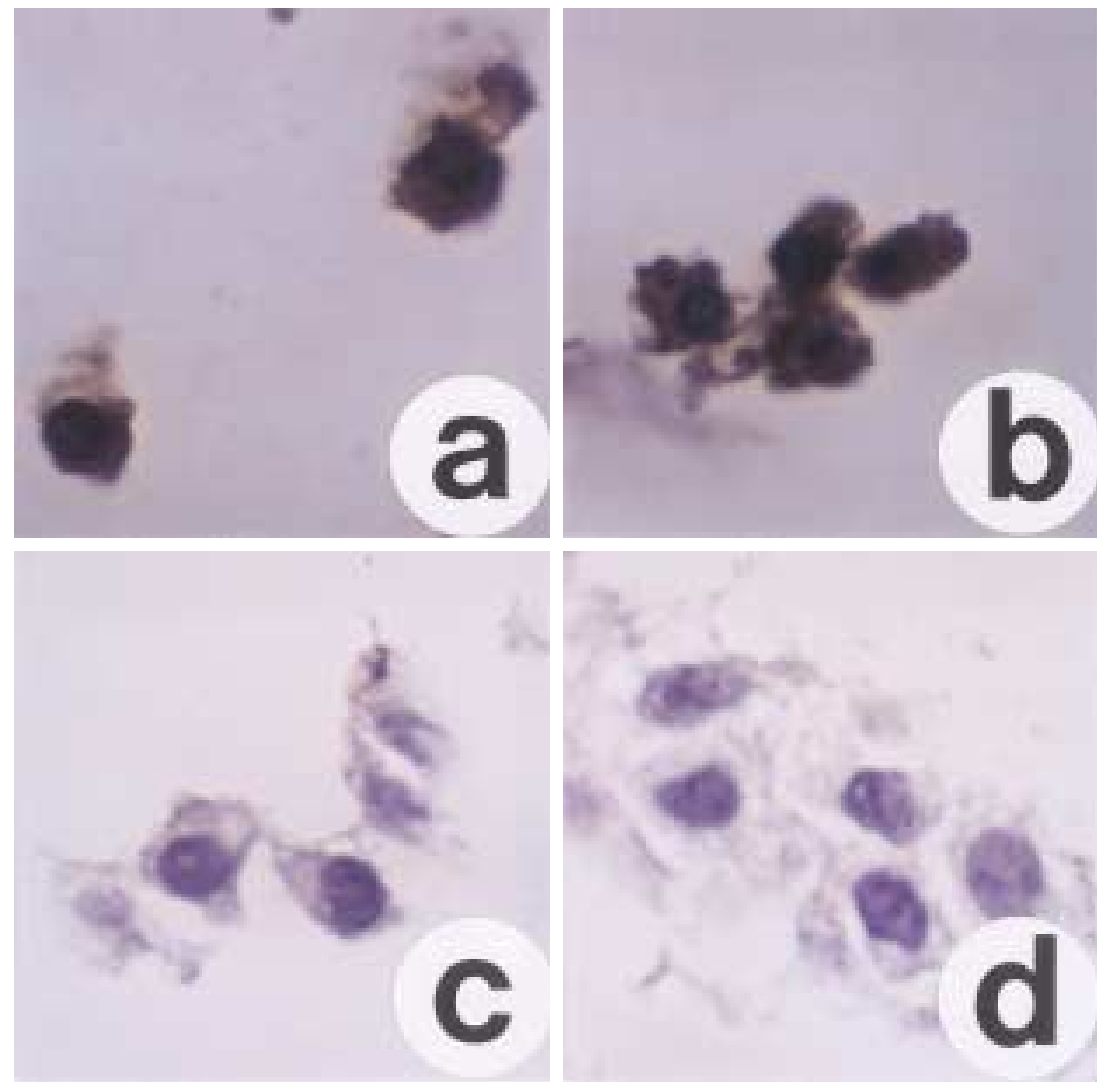

Fig. 5. - Immunocytochemical analysis of caspase-1 and caspase-3 in A549 cells. The expression of caspase-1 and caspase-3 (a and b, respectively) were detected in the cytoplasm and nucleus of A549 cells undergoing apoptosis morphologically, while these proteins (c and $\mathrm{d}$, respectively) were not detectable in untreated cells (data not shown) or cells administered control immunoglobulin $\mathrm{G}$ (IgG) with interferon- $\gamma($ IFN $-\gamma)$ pretreatment (original magnification, $\times 250$ ).

normal lung parenchyma (fig. 3). Positive signals for TUNEL were predominant in the inflammatory lesions. The number of TUNEL positive cells was significantly increased in IPF compared to normal lung parenchyma (fig. 3). There were significant correlations between the immunoreactivity grade for FADD, caspase-1, or caspase-3 and the number of TUNEL positive cells in all patients, including IPF and controls, but not in IPF alone.

\section{Apoptosis and caspase activity in A549 cells}

Twenty-four hours after the administration of CH-11 with IFN- $\gamma$ pretreatment, some of the A549 cells were detached from culture dishes, while untreated cells or cells administered control IgG with IFN- $\gamma$ pretreatment were both attached on dishes. Figure 4 demonstrates the results of flow cytometry for apoptosis using PI on A549 cells. Apoptosis was observed in $25 \%$ of A549 cells administered $\mathrm{CH}-11$ with IFN- $\gamma$ pretreatment. Figure 4 demonstrates the caspase- 1 and caspase- 3 activity in A549 cells. Both caspase-1 and caspase-3 activity was significantly increased at $24 \mathrm{~h}$ after the administration of $\mathrm{CH}-11$ with IFN- $\gamma$ pretreatment. Indeed, the activity of caspase- 3 was increased $\sim 7$-fold by the Fas-ligation compared with controls.

\section{Immunoreactivity for caspases in A549 cells}

The immunoreactivity for caspase-1 or caspase-3 was not detectable in untreated A549 cells. At $24 \mathrm{~h}$ after the treatment of $\mathrm{CH}-11$ with IFN- $\gamma$ pretreatment, chromatin condensation and fragmentation of nuclei as morphological characteristics for apoptosis were found on A549 cells, along with the immunoreactivity for caspase- 1 and caspase- 3 in both the cytoplasm and the nucleus (fig. 5).

\section{Western blot analysis for caspases on A549 cells}

At $24 \mathrm{~h}$ after the treatment of $\mathrm{CH}-11$ with IFN- $\gamma$ pretreatment, proform and activation fragment of caspases-1 were upregulated in detached cells, compared with those in attached cells, or cells administered control IgG with IFN- $\gamma$ pretreatment (fig. 6). Proforms and activation fragments of caspase- 8 and caspase- 3 were observed in detached cells $24 \mathrm{~h}$ after the treatment of $\mathrm{CH}-11$ with IFN- $\gamma$ pretreatment (fig. 6). These proforms or fragments were undetectable in attached 

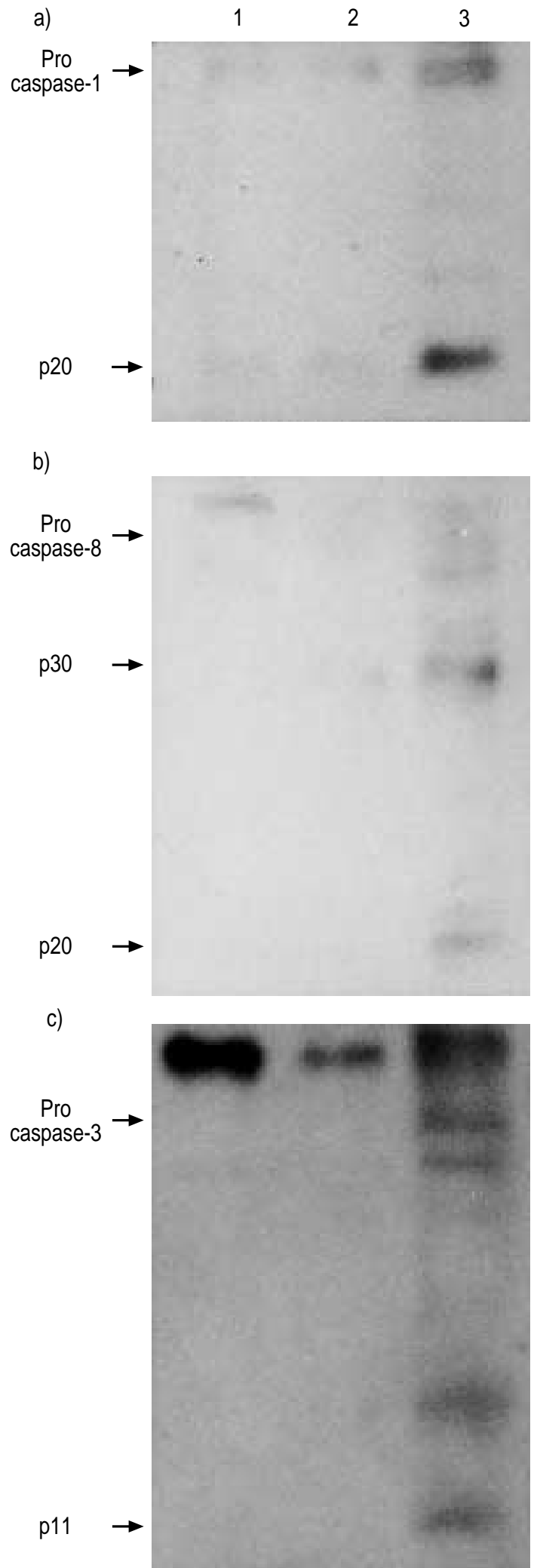

Fig. 6. - Results of western blot analysis with antibodies to caspase- 1 p20, caspase- 8 p20, and caspase- 3 p11 in A549 cells (a, b and c, respectively). Proforms of caspases were upregulated and activation fragments of caspases were observed in detached cells after the administration of $\mathrm{CH}-11$ with interferon- $\gamma$ (IFN- $\gamma$ ) pretreatment Lane 1: cells administered control immunoglobulin-G (IgG) with IFN- $\gamma$ pretreatment; lane 2: attached cells after the administration of $\mathrm{CH}-11$ with IFN- $\gamma$ pretreatment; lane 3: detached cells after the administration of $\mathrm{CH}-11$ with IFN- $\gamma$ pretreatment. cells and cells administered control IgG with IFN- $\gamma$ pretreatment.

\section{Discussion}

The study primarily demonstrated that FADD, caspase-1, and caspase-3 were highly expressed in bronchiolar and alveolar epithelial cells in lung tissues from patients with IPF, compared with normal lung parenchyma. It also showed that the number of TUNEL positive cells, which mainly consisted of lung epithelial cells, was significantly increased in IPF compared with normal lung parenchyma as compatible with previous work [4]. Furthermore, the number of TUNEL positive cells was correlated with the immunoreactivity grade for FADD, caspase-1 or caspase-3. Although positive signals for caspases do not always mean that the cells are dying, and all anti-caspase antibodies used in this study can recognize both active and inactive forms of caspases, these results suggest that the overexpression of caspases may reflect the upregulation of the apoptosis pathway in alveolar and bronchiolar epithelial cells in IPF.

Not only cytoplasmic, but also nuclear staining, was observed for caspase-1 and caspase-3 in bronchiolar and alveolar epithelial cells of IPF. To examine whether immunoreactivity for caspases localizes in the nucleus as well as the cytoplasm when the apoptosis signalling is stimulated, immunocytochemistry for caspases was performed, and the caspase activity on A549 cells was measured after Fas-ligation with IFN- $\gamma$ pretreatment. It was demonstrated that A549 cells, in which caspase-1 and caspase- 3 were activated, showed nuclear staining for caspase-1 and caspase-3. NAKAGAwARA et al. [20] also demonstrated that both caspase- 1 and caspase- 3 translocated from the cytoplasm to the nucleus in regressing or apoptotic tumour cells, using immunohistochemistry. Although cellular distribution of caspases has still been unclear, the fact that many of the substrates cleaved by caspase- 3 are localized in the nucleus, suggests that the caspase can translocate to the nucleus. Furthermore, previous studies have indicated that procaspases were transported from the cytoplasm to the nucleus, depending on a nuclear localization signal in their prodomain during the execution phase of apoptosis [21, 22]. The present results in vitro suggest that caspase- 1 and caspase- 3 may translocate into the nucleus during the apoptotic process in a human lung epithelial cell line. These results implicate that the nuclear expression of caspases in lung epithelial cells of IPF may reflect the activation of caspases and the executional process of apoptosis.

To investigate whether the cells expressing capasases are actually undergoing apoptosis, western blot analysis for the activation of caspase-1, caspase- 3 , and caspase- 8 on A549 cells was performed. All of these caspases were upregulated and activated in detached cells after the treatment of CH-11 with IFN- $\gamma$, compared with control cells or attached cells. FADD, which is a signal transducer downstream of Fas, binds to caspase-8 through its death effector domain, and makes a form of death-inducing signalling complex, leading to the activation of caspase- 8 . Therefore, the activation of 
caspase- 8 indicates that FADD is functional. The authors suggest that the Fas-signalling pathway and caspase cascade were upregulated and activated in apoptotic cells, but not in viable cells.

Alveolar macrophages and lymphocytes are major inflammatory cells present in inflammatory lesions of IPF. It is thought that these cells play an important role in the pathogenesis of IPF by regulating or promoting inflammatory and immune responses through the cytokine network. In the present study, alveolar macrophages showed positive signals for FADD, caspase-1, and caspase-3, while lymphocytes were positively stained for caspase-1 but negative for caspase-3 and FADD in IPF. In normal lung parenchyma, alveolar macrophages were positively stained for these molecules and lymphocytes were positive for caspase-1, although the intensity of these signals was weaker than those in IPF. These observations implicate that FADD and caspases may regulate apoptosis of alveolar macrophages and lymphocytes, to control the inflammatory reaction in the pathological state, and to maintain homeostasis in the physiological condition.

Another possibility of caspases expression in inflammatory cells may involve the activation of proinflammatory cytokines in these cells. Caspase-1 was described as the converter of pro-interleukin (IL)-1 $\beta$ and pro-IL-18 to the active form [23, 24]. Caspase-1 deficient mice have less IL- $1 \beta$, tumour necrosis factor- $\alpha$, and IL-6 [25]. Macrophages and lymphocytes release a variety of inflammatory cytokines including mature IL$1 \beta$. Similar to caspase-1, other caspases have been described to have a capacity to activate IL-1 $\beta$ [26]. In addition to the roles in apoptosis, overexpression of caspases in macrophages and lymphocytes may have proinflammatory functions associated with the pathophysiology of IPF.

In summary, this study demonstrated that the expressions of caspase-1, caspase-3, and Fas-associating protein with death domain were upregulated in bronchiolar and alveolar epithelial cells in idiopathic pulmonary fibrosis, compared to normal lung parenchyma. The positive staining in the nucleus in addition to the cytoplasm may implicate the activation of caspases, as well as upregulation of those expressions in vivo and in vitro. The cells in which caspases were upregulated and activated were actually undergoing apoptosis in vitro. The expression of Fas-associating protein with death domain and caspases were also detected in macrophages in idiopathic pulmonary fibrosis, as well as normal lung parenchyma. This suggests that these molecules play some role in pathological and physiological states, and may have proinflammatory roles in addition to mediating apoptosis. The upregulation of Fas-signalling molecules may play an important role in mediating apoptosis of lung epithelial cells and may be associated with the pathophysiology of idiopathic pulmonary fibrosis.

\section{References}

1. Thompson CB. Apoptosis in the pathogenesis and treatment of disease. Science 1995; 267: 1456- 1462.
2. Williams GT. Programmed cell death: apoptosis and oncogenesis. Cell 1991; 65: 1097-1098.

3. Williams GT. Apoptosis in the immune system. J Pathol 1994; 173: 1-4.

4. Kuwano K, Kunitake R, Kawasaki M, Nomoto Y, Hagimoto N, Hara N. P21 Wafl/Cipl/Sdil and p53 expression in association with DNA strand breaks in idiopathic pulmonary fibrosis. Am J Respir Crit Care Med 1996; 154: 477-483.

5. Kuwano K, Miyazaki H, Hagimoto $\mathrm{N}$, et al. The involvement of Fas-Fas ligand pathway in fibrosing lung diseases. Am J Respir Cell Mol Biol 1999; 20: $53-$ 60 .

6. Jacobson MD, Evan GI. Apoptosis. Breaking the ICE. Curr Biol 1994; 4: 337-340.

7. Enari M, Hug H, Nagata S. Involvement of an ICElike protease in Fas-mediated apoptosis. Cell 1995; 87: $78-80$.

8. Los M, Van de Craen M, Penning LC, et al. Requirement of an ICE/CED-3 protease for Fas/APO-1-mediated apoptosis. Nature 1995; 375: $81-83$.

9. Hasegawa J, Kamada S, Kamiike W, et al. Involvement of CPP32/Yama (-like) proteases in Fas-mediated apoptosis. Cancer Res 1996; 56: $1713-$ 1718.

10. Yuan J, Shaham S, Ledoux S, Ellis HM, Horvitz HR. The $C$. elegans cell death gene ced-3 encodes a protein similar to mammalian interleukin-1 $\beta$-converting enzyme. Cell 1993; 75: 641-652.

11. Thornberry NA, Lazebink Y. Caspases: enemies within. Science 1998; 281: 1312-1316.

12. Humke EW, Ni J, Dixit VM. ERICE, a novel FLICEactivatable caspase. J Biol Chem 1998; 273: $15702-$ 15707.

13. Ahmad M, Srinivasula SM, Hegde R, Mukattash R, Fernandes-Alnemri T, Alnemri ES. Identification and characterization of murine caspase-14, a new member of the caspase family. Cancer Res 1998; 58: $5201-$ 5205.

14. Alnemri ES, Livingston DJ, Nicholson DW, et al. Human ICE/CED-3 protease nomenclature. Cell 1996; 87: 171.

15. Cohen GM. Caspases: the executioners of apoptosis. Biochem J 1997; 326: 1-16.

16. Yeh WC, de la Pompa JL, McCurrach ME, et al. FADD: essential for embryo development and signalling from some, but not all, inducers of apoptosis. Science 1998; 279: $1954-1958$.

17. Crystal RG, Bitterman PB, Rennard SI, Hance AJ, Keogh BA. Interstitial lung diseases of unknown cause. Disorders characterized by chronic inflammation of the lower respiratory tract (first of two parts). N Engl J Med 1984; 310: 154-166.

18. Shin RW, Iwaki T, Kitamoto T, Tateishi J. Methods in laboratory investigation. Hydrated autoclave pretreatment enhances TAU. Immunoreactivity in formalin-fixed normal and Alzheimer's disease brain tissues. Lab Invest 1991; 64: 693-702.

19. Wen LP, Madani K, Fahrni JA, Duncan SR, Rosen GD. Dexamethasone inhibits lung epithelial cell apoptosis induced by IFN- $\gamma$ and Fas. Am J Physiol 1997; 273: L921 - 929.

20. Nakagawara A, Nakamura $\mathrm{Y}$, Ikeda $\mathrm{H}$, et al. High levels of expression and nuclear localization of interleukin-1 $\beta$ converting enzyme (ICE) and CPP32 
in favorable human neuroblastoma. Cancer Res 1997; 57: $4578-4584$.

21. Mao PL, Jiang Y, Wee BY, Porter AG. Activation of caspase-1 in the nucleus requires nuclear translocation of pro-caspase-1 mediated by its prodomain. J Biol Chem 1998; 273: $23621-23624$.

22. Colussi PA, Harvey NL, Kumar S. Prodomaindependent nuclear localization of the caspase-2 (Nedd2) precursor. A novel function for a caspase prodomain. J Biol Chem 1998; 273: 24535-24542.

23. Thornberry NA, Bull HG, Calaycay JR, et al. A novel heterodimeric cysteine protease is required for interleukin-1- $\beta$ processing in monocytes. Nature 1992; 356: $768-774$.

24. Gu Y, Kuida $\mathrm{K}$, Tsutsui $\mathrm{H}$, et al. Activation of interferon- $\gamma$ inducing factor mediated by interleukin$1 \beta$ converting enzyme. Science 1997; 275: 206-209.

25. Kuida K, Lippke JA, Ku G, et al. Altered cytokine export and apoptosis in mice deficient in inteeukin-1 $\beta$ converting enzyme. Science 1995; 267: 2000-2003.

26. Miwa K, Asano M, Horai R, Iwakura Y, Nagata S, Suda T. Caspase-1 independent IL-1 $\beta$ release and inflammation induced by the apoptosis inducer Fas ligand. Nature Med 1998; 4: 1287-1292. 